\title{
A further application of composite-stimulus control in additive summation
}

\author{
SHIH-YUAN TSAI and STANLEY J. WEISS \\ The American University, Washington, D.C. 20016
}

\begin{abstract}
Six rats were trained to leverpress on a three-component multiple schedule containing variable-interval (VI) 28-sec, VI 66-sec, and extinction components. Under this arrangement all subjects came to respond during the VI periods, while responding essentially ceased in the extinction associated stimulus. Tone and light $(\mathrm{T}+\mathrm{L})$ were both present during the VI 28-sec contingency and both were absent (tone off and light out, $\overline{\mathrm{T}}+\overline{\mathrm{L}}$ ) during the VI 66-sec contingency. For half the rats extinction was programmed in light $(\mathrm{L}+\overline{\mathrm{T}})$, for the other half extinction was programmed in tone $(\mathrm{T}+\overline{\mathrm{L}})$. A composite-stimulus analysis of the training conditions reveals that, for the $\mathrm{L}+\mathrm{T}$ extinction rats, the composite composed entirely of stimulus elements associated with responding was $\mathrm{T}+\overline{\mathrm{L}}$ (tone), while for the $\mathrm{T}+\overline{\mathrm{L}}$ extinction rats this stimulus was $L+\bar{T}$ (light). In testing all subjects emitted the most responses to that composite stimulus composed entirely of elements discriminative for responding, rather than to the VI associated composites that had an element in common with the extinction component. That it was tone or light to which the subjects showed additive summation supports predictions from Weiss' $(1969,1972)$ composite-stimulus control model.
\end{abstract}

When tone and light are each discriminative for an increase in response rate over the rate maintained in their simultaneous absence, more responses are emitted to tone-plus-light on a stimulus compounding test than to tone or light alone (Miller \& Ackley, 1970; Weiss, 1964; Wolf, 1963). This phenomenon has been termed additive summation and has been demonstrated in rats with leverpressing maintained by food. When the tone and light are treated as composite, rather than unitary, stimuli in this conditioning situation, a unique relationship is revealed between these stimuli and tone-pluslight. According to this composite formulation, the simultaneous absence of tone and light is identified as $\overline{\mathrm{T}}+\overline{\mathrm{L}}$, tone and light are considered as $\mathrm{T}+\overline{\mathrm{L}}$ and $\mathrm{L}+\overline{\mathrm{T}}$, respectively, and tone-plus-light is represented at $\mathrm{T}+\mathrm{L}$. Weiss (1969) pointed out that $T+\overline{\mathrm{L}}$ and $\mathrm{L}+\overline{\mathrm{T}}$ each contained one element associated with an increase in response ( $\mathrm{T}$ and $\mathrm{L}$, respectively) and another associated with a decrease in response ( $\overline{\mathrm{L}}$ and $\overline{\mathrm{T}}$, respectively). In comparison, $\mathrm{T}+\mathrm{L}$, which controlled additive summation, was composed entirely of elements associated with response increase. This is shown in row 1 of Table 1 . Weiss (1969) explored this notion of stimulus control further by training animals on a schedule where $T+\overline{\mathrm{L}}$ and $L+T$ were discriminative for response increase, but the composite associated with response cessation was $T+L$. As row 2 of Table 1 shows, under this arrangment the composite now composed entirely of elements

This research was supported by Grant MH-16853 from the National Institute of Mental Health, United States Public Health Service. Reprints may be obtained from Stanley J. Weiss, Department of Psychology, The American University, Washington, D.C. 20016. associated with response increase was $\bar{T}+\overline{\mathrm{L}}$, and Weiss predicted that configuration would control additive summation. The prediction was confirmed. $\overline{\mathrm{T}}+\overline{\mathrm{L}}$ controlled approximately $60 \%$ of the $\mathrm{T}+\overline{\mathrm{L}}, \mathrm{L}+\overline{\mathrm{T}}$, and $\overline{\mathrm{T}}+\overline{\mathrm{L}}$ test responses. Moreover, this percentage to $\overline{\mathrm{T}}+\overline{\mathrm{L}}$ was substantially the same as that reported to $\mathrm{T}+\mathrm{L}$ in a comparably performed mirror-image experiment reported by Weiss (1971, Experiment 2).

Weiss (1972) argued that the generality of the model might be tested in those situations where composites other than $\mathrm{T}+\mathrm{L}$ or $\overline{\mathrm{T}}+\overline{\mathrm{L}}$ were associated with response

Table 1

Composite Representation of Stimuli Used in Stimulus Compounding Experiments

\begin{tabular}{|c|c|c|}
\hline $\begin{array}{l}\text { Composi } \\
\text { Associated With } \\
\text { Response } \\
\text { Cessation* }\end{array}$ & $\begin{array}{l}\text { imulus } \\
\text { Discriminative } \\
\text { for Response } \\
\text { Increase* }\end{array}$ & $\begin{array}{l}\text { Composite Composed } \\
\text { Exclusively of Ele- } \\
\text { ments Associated } \\
\text { With Response } \\
\text { Increase* }\end{array}$ \\
\hline \multicolumn{2}{|c|}{ Training } & \\
\hline 1. $\overline{\mathrm{T}}+\overline{\mathrm{L}}$ & $\begin{array}{l}T+\overline{\mathrm{L}} \\
\mathrm{L}+\overline{\mathrm{T}}\end{array}$ & $T+L$ \\
\hline 2. $\mathrm{T}+\mathrm{L}$ & $\begin{array}{l}T+\bar{L} \\
L+\bar{T}\end{array}$ & $\overline{\mathrm{T}}+\overline{\mathrm{L}}$ \\
\hline 3. $\mathrm{T}+\overline{\mathrm{L}}$ & $\begin{array}{l}\bar{T}+\bar{L} \\
T+L\end{array}$ & $\mathbf{L}+\overline{\mathbf{T}}$ \\
\hline 4. $\mathrm{L}+\overline{\mathrm{T}}$ & $\begin{array}{l}\bar{T}+\bar{L} \\
T+L\end{array}$ & $T+\bar{L}$ \\
\hline
\end{tabular}

${ }^{*} \bar{T}+\bar{L}=$ tone off and light out $T+\bar{L}=$ tone on and light out $L+\bar{T}=$ light on and no tone $T+L=$ tone plus light 
cessation. If $\mathrm{T}+\mathrm{L}$ and $\overline{\mathrm{T}}+\overline{\mathrm{L}}$ were discriminative for response increase, while $\mathrm{T}+\overline{\mathrm{L}}$ controlled cessation, the composite composed entirely of elements associated with response increase would be $\mathrm{L}+\overline{\mathrm{T}}$ (light), as shown in row 3 of Table 1 . Row 4 in Table 1 shows that if $\mathrm{T}+\mathrm{L}$ and $\overline{\mathrm{T}}+\overline{\mathrm{L}}$ were discriminative for response increase but $L+\bar{T}$ was associated with response cessation, additive summation should occur to $\mathrm{T}+\overline{\mathrm{L}}$ (tone).

Meltzer and Masaki (1972) confirmed these extensions of a composite-stimulus control notion. However, the magnitude of the summative effects they reported to $\mathrm{T}+\overline{\mathrm{L}}$ and $\mathrm{L}+\overline{\mathrm{T}}$ was much less substantial than those reported by Weiss $(1969,1971$, Experiment 2$)$. Was this due to limitations in application of the model or differences in procedures? The present experiment explored these possibilities by employing procedures more comparable to those that have been shown to produce strong additive summation.

\section{METHOD}

\section{Subjects}

Six experimentally naive male hooded rats, about $350 \mathrm{~g}$ at the beginning of the experiment, were maintained at approximately $80 \%$ of their free-feeding weights. Water was continuously available in the individual home cages.

\section{Apparatus \\ Three similar $20 \times 21 \times 17.5 \mathrm{~cm}$ operant chambers were employed, each with a microswitch lever and a food trough on the front wall. The side walls were white translucent plastic, the front and rear walls aluminum, and the ceiling perforated transparent plastic. The floor was composed of stainless steel rods. The chambers were placed in sound-attenuation chests described by Weiss (1970). The light stimulus was generated by two $25-\mathrm{W} 120-\mathrm{V}$ bulbs that provided approximately $130.2 \mathrm{~cd} / \mathrm{m}^{2}$. The tone was $2,000 \mathrm{~Hz}$ at $90-95 \mathrm{~dB}$. A dim houselight was on continuously. Comparable apparatus and stimuli are described in greater detail elsewhere (Emurian \& Weiss, 1972). Reinforcers were Noyes $45-\mathrm{mg}$ rat pellets. The programming was done by a PDP-8/E computer located in a room adjacent to that housing the training chambers.}

\section{Procedure}

Baseline training. The rats were magazine trained and shaped to press the lever during the first session. On the next session reinforcement was arranged according to a variable-interval (VI) 15 -sec schedule. During Sessions 3 and 4 this was changed to VI 28-sec. Beginning on Session 5 a three-component multiple schedule composed of VI 28-sec, VI 66-sec, and extinction (S $\Delta$ ) periods was instituted. The values of VI $28-\mathrm{sec}$ ranged from 1 to $80 \mathrm{sec}$. The range of VI 66 -sec intervals was 1 to $180 \mathrm{sec}$. Tone and light $(\mathrm{T}+\mathrm{L})$ were both on during the VI 28 -sec component, while neither light nor tone $(\overline{\mathrm{T}}+\overline{\mathrm{L}})$ was on during the VI 66-sec component. For Subjects 271, 272, and 273, light $(\mathrm{L}+\overline{\mathrm{T}})$ was the stimulus signaling extinction. For Subjects 274,275 , and 276 , tone $(T+\overline{\mathrm{L}})$ was on during extinction. The $\mathrm{T}+\mathrm{L}$ and $\overline{\mathrm{T}}+\overline{\mathrm{L}}$ components appeared in random order, but were always separated by the $\mathrm{S} \Delta$ condition. The duration of all components varied nonsystematically within the limits of 1 to $10 \mathrm{~min}$. After 272 - to 3-h sessions on this multiple schedule, a correction procedure was instituted in the extinction component to suppress persistent responding. The correction procedure required that responding cease in an extinction period for a time averaging $60 \mathrm{sec}$, varying within sessions between 30 and $100 \mathrm{sec}$, before one of the VI components would commence. Other features of the multiple schedule remained un- changed. All subjects were trained on the multiple schedule until they satisfied the discrimination criteria described below. This required between 7 and 21 additional 2- to 3 -h sessions.

Discrimination criteria. A subject was trained until for 4 consecutive days a visual inspection of cumulative records showed (1) an abrupt and sustained response rate increase upon at least $75 \%$ of the presentations of the reinforcement associated stimuli $(T+L$ or $\bar{T}+\bar{L})$, and (2) an abrupt and sustained response reduction upon at least $75 \%$ of the $S \Delta$ presentations $(\mathrm{T}+\overline{\mathrm{L}}$ or $\mathrm{L}+\overline{\mathrm{T}})$.

Test. After the rat had met the discrimination criteria, a test was administered with food reinforcement discontinued. The test consisted of 13 block-randomized presentations of $\mathrm{T}+\mathrm{L}, \overline{\mathrm{T}}+\overline{\mathrm{L}}$, and the composite composed exclusively of elements associated with response increase $(T+\bar{L}$ for Subjects 271, 272, and 273; $\mathrm{L}+\overline{\mathrm{T}}$ for Subjects 274, 275, and 276). These stimuli were each separated by the animal's extinctionassociated stimulus $(\mathrm{L}+\overline{\mathrm{T}}$ for Subjects 271,272 , and 273 ; $\mathrm{T}+\overline{\mathrm{L}}$ for 274,275 , and 276). Each stimulus was on for $2 \mathrm{~min}$. The test began after an animal received $30 \mathrm{~min}$ of reinforced training on its terminal baseline schedule. It lasted $156 \mathrm{~min}$

\section{RESULTS AND DISCUSSION}

\section{Terminal Baseline Training Performance}

Table 2 shows that response rates in $S^{\Delta}$ were substantially lower than those in $T+L$ or $\bar{T}+\bar{L}$ for all subjects on their criterion sessions. Stimulus control was comparable for both groups. With the exception of Subject 272, all rats responded at appreciably higher rates in their VI 28-sec periods $(\mathrm{T}+\mathrm{L})$ than in their VI 66-sec periods $(\overline{\mathrm{T}}+\overline{\mathrm{L}})$.

\section{Test Performance}

Table 3 shows that all animals emitted the most test responses to the composite composed entirely of response associated elements, with the outputs to the VI 28-sec, VI 66-sec, and extinction $(S \Delta)$ associated stimuli following in that order for each animal. In light of the rank-order consistency of the four test conditions over $\mathrm{L}+\overline{\mathrm{T}}$ and $\mathrm{T}+\overline{\mathrm{L}}$ extinction groups, all subjects were combined for a Friedman two-way ANOVA. This yielded a $\chi_{\mathrm{r}}^{2}=18.0$ that was significant at $\mathrm{p}<.001$. A Wilcoxon test indicated that at the .05 level significantly more responses were emitted (1) to the composite

Table 2

Terminal Training Performance* (Responses Per Minute)

\begin{tabular}{|c|c|c|c|}
\hline \multirow[b]{2}{*}{ Subject } & \multicolumn{3}{|c|}{ Stimulus and Schedule Conditions } \\
\hline & $\begin{array}{c}\text { VI } 28 \text {-sec } \\
\mathrm{T}+\mathrm{L}\end{array}$ & $\begin{array}{c}\text { VI } 66 \text {-sec } \\
\overline{\mathrm{T}}+\overline{\mathrm{L}}\end{array}$ & $\begin{array}{c}\text { Extinction } \\
\mathrm{L}+\overline{\mathrm{T}} \text { or } \mathrm{T}+\overline{\mathrm{L}}\end{array}$ \\
\hline \multicolumn{4}{|c|}{ A. $L+\bar{T}$ Extinction Group } \\
\hline $\begin{array}{l}271 \\
272 \\
273\end{array}$ & $\begin{array}{l}34.4 \\
20.0 \\
11.0\end{array}$ & $\begin{array}{r}18.5 \\
22.1 \\
5.8\end{array}$ & $\begin{array}{l}2.6 \\
3.7 \\
1.2\end{array}$ \\
\hline \multicolumn{4}{|c|}{ B. $T+\overline{\mathrm{L}}$ Extinction Group } \\
\hline $\begin{array}{l}274 \\
275 \\
276\end{array}$ & $\begin{array}{l}43.0 \\
24.2 \\
21.8\end{array}$ & $\begin{array}{l}17.5 \\
12.7 \\
12.4\end{array}$ & $\begin{array}{l}3.0 \\
4.0 \\
3.0\end{array}$ \\
\hline
\end{tabular}

*The rates are averages of the final four training sessions after a 30-min warm-up. 
Table 3

Test Responses

Stimulus Conditions

\begin{tabular}{|c|c|c|c|c|c|c|c|}
\hline \multirow[b]{3}{*}{ Subject } & \multicolumn{7}{|c|}{ Stimulus Conditions } \\
\hline & \multicolumn{2}{|c|}{$\begin{array}{l}\text { Compound of SD Elements Exclusivel } \\
\text { Associated With Responding }\end{array}$} & \multicolumn{2}{|c|}{ VI $28-S e c S^{D}$} & \multicolumn{2}{|c|}{ VI 66-Sec SD } & \multirow{2}{*}{$\begin{array}{c}S \Delta \\
L+\bar{T} \text { or } T+\bar{L}\end{array}$} \\
\hline & $T+\bar{L}$ & or $\mathrm{L}+\overline{\mathrm{T}}$ & & $+\mathrm{L}$ & & $\overline{\mathrm{T}}+\overline{\mathrm{L}}$ & \\
\hline \multicolumn{8}{|c|}{ A. $\mathrm{L}+\overline{\mathrm{T}}$ Extinction Group } \\
\hline $\begin{array}{l}271 \\
272 \\
273\end{array}$ & $\begin{array}{l}367 \\
303 \\
142\end{array}$ & $\begin{array}{l}(62.6 \%)^{*} \\
(50.3 \%) \\
(56.8 \%)\end{array}$ & $\begin{array}{r}121 \\
196 \\
86\end{array}$ & $\begin{array}{l}(20.7 \%) \\
(32.5 \%) \\
(34.4 \%)\end{array}$ & $\begin{array}{r}98 \\
104 \\
22\end{array}$ & $\begin{array}{l}(16.7 \%) \\
(17.2 \%) \\
(8.8 \%)\end{array}$ & $\begin{array}{l}5 \dagger \\
1.3 \\
2.3\end{array}$ \\
\hline \multicolumn{8}{|c|}{ B. $\mathrm{T}+\overline{\mathrm{L}}$ Extinction Group } \\
\hline $\begin{array}{l}274 \\
275 \\
276\end{array}$ & $\begin{array}{l}348 \\
366 \\
186\end{array}$ & $\begin{array}{l}(57.6 \%) \\
(52.9 \%) \\
(52.8 \%)\end{array}$ & $\begin{array}{l}198 \\
276 \\
144\end{array}$ & $\begin{array}{l}(32.8 \%) \\
(39.9 \%) \\
(40.9 \%)\end{array}$ & $\begin{array}{l}58 \\
50 \\
22\end{array}$ & $\begin{array}{l}(9.6 \%) \\
(7.2 \%) \\
(6.3 \%)\end{array}$ & $\begin{array}{r}8.7 \\
15.3 \\
2.3\end{array}$ \\
\hline Mean & 285.3 & $(55.5 \%)$ & 170.2 & $(33.5 \%)$ & 59 & $(11.0 \%)$ & 5.8 \\
\hline
\end{tabular}

*Numbers in parentheses are percentages calculated for each subject by dividing the responses to each separate stimulus (tone-pluslight, light out/no tone, and the "compound") by the sum total of responses to these stimuli, and multiplying by 100. fIn order to equate for the time subjects spent in each condition, number of responses in this column is the total to $S \Delta$ divided by three.

composed of response associated elements than to $\mathrm{T}+\mathrm{L}, \overline{\mathrm{T}}+\overline{\mathrm{L}}$, or $\mathrm{S} \Delta,(2)$ to $\mathrm{T}+\mathrm{L}$ than to $\overline{\mathrm{T}}+\overline{\mathrm{L}}$ or $\mathrm{S} \Delta$, and (3) to $\bar{T}+\bar{L}$ than to $S \Delta$.

Figure 1 indicates that the additive effect was evidenced from the beginning of the test for both groups. In addition, the relative magnitude of this effect increased as the test progressed. Dividing the responses each rat emitted to the composite composed of response associated elements $(\mathrm{T}+\overline{\mathrm{L}}$ or $\mathrm{L}+\overline{\mathrm{T}})$ by the sum of the responses emitted to $\mathrm{T}+\mathrm{L}$ and $\overline{\mathrm{T}}+\overline{\mathrm{L}}$ yielded ratios that averaged $1: 1$ during the first four replications, while during the last four replications the average ratio was $3: 1$. For five of the six subjects this ratio was larger during the last four test replications than in the initial four, suggesting that the $T+\bar{L}$ and $L+\bar{T}$ composites were more resistant to extinction than $T+L$ and $\bar{T}+\bar{L}$.

The magnitude and intersubject consistency of the additive summation in both groups of the present experiment was close to that of previous studies showing summation to $\mathrm{T}+\mathrm{L}$ (Weiss, 1971, Experiment 2) and $\bar{T}+\bar{L}$ (Weiss, 1969), indicating that equivalent stimulus functions can be served by $T, L, \bar{T}$, or $\bar{L}$ composite elements on the type of baselines under consideration. This control appears to be determined by the specific contingencies associated with each element.

In the present experiment $\mathrm{T}+\overline{\mathrm{L}}$ or $\mathrm{L}+\overline{\mathrm{T}}$ controlled over $55 \%$ of the test responses, more than the combined total of those emitted to $T+L$ and $\bar{T}+\bar{L}$. In the Meltzer and Masaki (1972) study, $\mathrm{T}+\overline{\mathrm{L}}$ or $\mathrm{L}+\overline{\mathrm{T}}$ controlled only $39 \%$ of the test responses, $36 \%$ less than the combined total to $\mathrm{T}+\mathrm{L}$ and $\overline{\mathrm{T}}+\overline{\mathrm{L}}$. The current results suggest that those weak summative effects were due to the procedures Meltzer and Masaki used in training and testing rather than to differences in stimulus control processes operating when summation occurs to tone-plus-light as compared to tone or light. The discriminative control in training appeared weaker in the Meltzer and Masaki study than in the present experiment. Unfortunately, they did not present rates to $\mathrm{S} \Delta$ for their individual subjects, but they did indicate that $\mathrm{S}^{\Delta}$ controlled rates between 7.5 and 17.3 responses/min, while one subject even responded more frequently in $\mathrm{S}^{\Delta}$ than in its VI components.

The probe test Meitzer and Masaki (1972) employed probably also contributed to the weakness of their results. On the extinction tests of the current experiment, the relative magnitude of the summative effect grew larger as the test progressed because responding in $\mathrm{T}+\mathrm{L}$ and $\overline{\mathrm{T}}+\overline{\mathrm{L}}$ appeared to extinguish more rapidly than that to $\mathrm{T}+\overline{\mathrm{L}}$ or $\mathrm{L}+\overline{\mathrm{T}}$. This differential extinction has also been indicated in other experiments reporting summative effects where an extinction test was used (Miller \& Ackley, 1970; Weiss, 1964). In comparison, the probe tests employed by Meltzer and Masaki presented each test stimulus only once per session, interspersed among reinforced components. This would have retarded extinction to $T+L$ and $\bar{T}+\bar{L}$, which were nonreinforced only occasionally, while speeding up extinction to $\mathrm{T}+\overline{\mathrm{L}}$ and $\mathrm{L}+\overline{\mathrm{T}}$, which were always nonreinforced.

That powerful additive summation occurred to $\mathrm{T}+\overline{\mathrm{L}}$ (tone) and $\mathrm{L}+\overline{\mathrm{T}}$ (light) in the current experiment indicates that it is an oversimplification to view these as unitary stimuli, as is customarily the case. Rather, it might be more profitable to view the rates resulting in these situations as a "mix" of the behaviors conditioned to each composite element. A stimulus element discriminative for an increase in rate and an $\mathrm{S}^{\Delta}$ element associated with response cessation were contained in $T+L$ and $\bar{T}+\bar{L}$ composites for both groups of the present experiment. However, the recombination of elements during the test created a composite composed entirely of response associated 

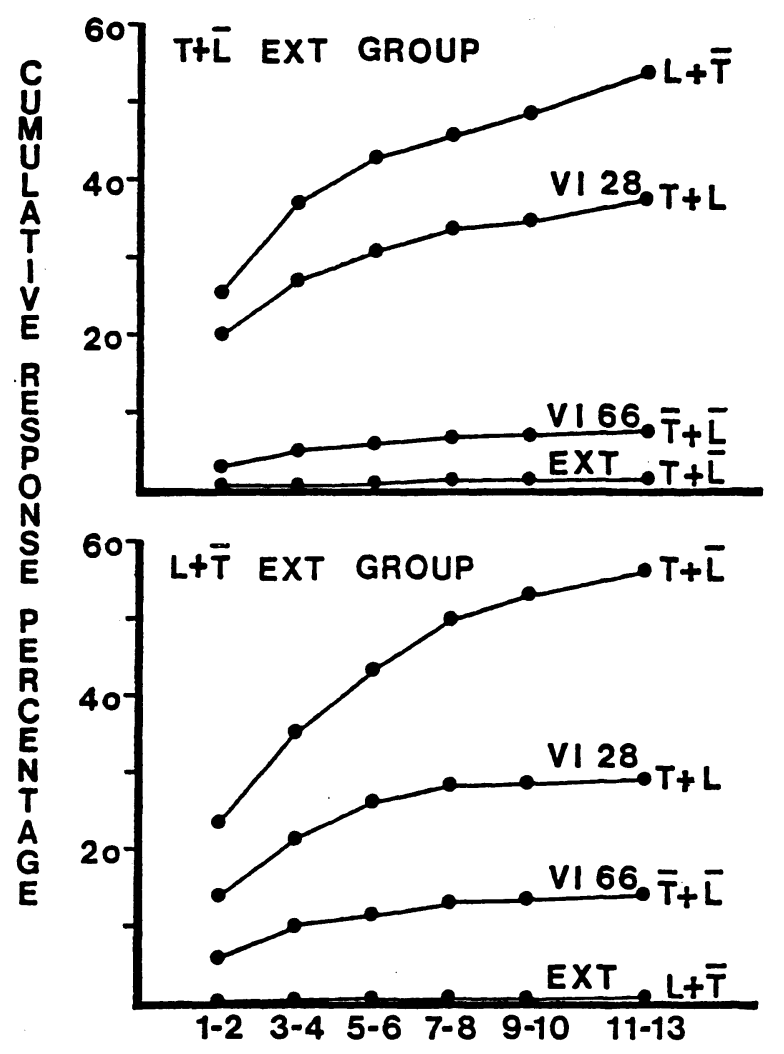

TEST REPLICATIONS

Figure 1. The mean percentage of responses emitted to each test condition accumulated over replications. The training schedule and the stimulus condition represented by each curve are indicated by the notation to the extreme right. The curves of $L+\bar{T}$ (light) extinction Subjects 271,272 , and 273 are presented in the lower frame, while the curves for the $T+\bar{L}$ (tone) extinction Subjects 274, 275, and 276 are presented in the upper frame. The entries in these figures were generated according to the following procedure. (1) A subject's response output to each stimulus condition was accumulated up to the indicated replication. (2) The accumulated responses were divided by that animal's total test responses. (3) These proportions were multiplied by 100 . (4) Finally, the resulting percentages calculated for each subject at each point were averaged over subjects. elements $(T+\bar{L}$ or $L+\bar{T})$. This composite, in every instance, controlled higher rates in testing than the VI associated composites, each of which contained a response cessation associated element. This could be interpreted as indicating that the response cessation associated elements were operating actively in VI components to depress the response rates, since their removal led to a rate increase. Thus, the results of the current experiment support Weiss' composite-stimulus control analysis. As he predicted (1972, pp. 194-195), training under any of the four arrangements shown in Table 1 can lead to roughly comparable additive summation to that test composite composed entirely of stimulus elements discriminative for an increase in responding, even those composites, such as tone or light, usually conceived of as unitary stimuli.

\section{REFERENCES}

EMuRian, H. H., \& Weiss, S. J. Compounding discriminative stimuli controlling free-operant avoidance. Journal of the Experimental Analysis of Behavior, 1972, 17, 249-256.

Meltzer, D., \& Masaki, M. A. Stimulus parameters producing response summation. Psychonomic Science, 1972, 29, 155-157.

Miller, L., \& ACKLEY, R. Summation of responding maintained by fixed-interval schedules. Journal of the Experimental Analysis of Behavior, 1970, 13, 199-203.

WEISS, S. J. Summation of response strengths instrumentally conditioned to stimuli in different sensory modalities. Journal of Experimental Psychology, 1964, 68, 151-155.

WEISs. S. J. Attentional processes along a composite stimulus continuum during free-operant summation. Journal of Experimental Psychology, 1969, 82, 22-27.

WEISS, S. J. An effective and economical sound attenuation chamber. Journal of the Experimental Analysis of Behavior, 1970, 13, 37-39.

WEISS, S. J. Discrimination training and stimulus compounding: Consideration of non-reinforcement and response differentiation consequences of $\mathrm{S} \Delta$. Journal of the Experimental Analysis of Behavior, 1971, 15, 387-402.

WEISS, S. J. Stimulus compounding in free-sperant and classical conditioning: A review and analysis. Psychological Bulletin, 1972, 78, 189-208.

Wolf, M. M. Some effects of combined $S D_{\mathrm{S}}$. Journal of the Experimental Analysis of Behavior, 1963, 6, 343-347.

(Received for publication October 1, 1976.) 